\title{
LA ARGUMENTACIÓN JURÍDICA: ALGUNOS CONTEXTOS DE APLICACIÓN ${ }^{1}$
}

\author{
LEGAL ARGUMENT: \\ SOME CONTEXTS OF APPLICATION
}

Nuria Belloso Martín ${ }^{2}$

\begin{abstract}
RESUMEN - La temática de la argumentación jurídica admite múltiples perspectivas. En este trabajo prestaremos especial atención al tipo de comunicación que se desarrolla en una de las formas de resolución de conflictos, como es la mediación, diferenciándola de la tipología de comunicación que se sigue en un proceso judicial. Partimos de unas consideraciones iniciales sobre la necesidad y conveniencia de la interpretación jurídica. Continuaremos con una breve revisión histórica de la argumentación jurídica. Los acuerdos y desacuerdos en cuanto al significado de enunciados jurídicos y normas jurídicas son frecuentes en el Derecho. Cada una de las diversas corrientes iusfilosóficas ofrece una solución. Los diversos operadores jurídicos (abogados, Ministerio Público, jueces) deben argumentar jurídicamente. Finalizaremos analizando la argumentación jurídica y la acción comunicacional en el proceso judicial y en la mediación.
\end{abstract}

PALABRAS CLAVE - Argumentación jurídica. Principio. Reglas. Comunicación.

\begin{abstract}
The thematic of the juridical argument admits multiple perspectives. In this work we will pay special attention to the communication type that is developed in one in the ways of resolution of conflicts, like it is the mediation, differentiating it of the communication typology that is continued in a judicial process. We leave of some initial considerations about the necessity and convenience of the juridical interpretation. We depart from a few initial considerations on the need and expediency of the juridical interpretation. The agreements and disagreements as for the meaning of having enunciated juridical and juridical norms are frequent in the Right. Each one of the diverse average iusphilosophical offers a solution. The diverse juridical operators (lawyers, Public Ministry, judges) they should argue legally. We will finish analyzing the juridical argumentation and the communication action in the judicial process and in the mediation.
\end{abstract}

KEYWORDS - Juridical argumentation. Principle. Rule. Communication.

\section{SOBRE LA INTERPRETACIÓN JURÍDICA}

\footnotetext{
1 Una versión inicial y reducida de este trabajo ha sido publicada en: BELLOSO MARTíN, N., "Revisitando la teoría de la argumentación: mediación jurídica versus proceso judicial", en M. Otero Parga, (Coordinadora), en Tópica, Retórica y Dialéctica en la jurisprudencia, Ed. Universidad de Santiago de Compostela, Santiago, 2011, pp. 89-103.

${ }^{2}$ Profesora Titular de Filosofía del Derecho en la Facultad de Derecho de la Universidad de Burgos. Directora del Departamento de Derecho Público. E-mail: nuriabellosomartin@yahoo.com.br.
} 
En el desempeño de numerosos trabajos y profesiones nos vemos obligados a argumentar para hacer prevalecer la opinión que sustentemos en un determinado momento. En el caso de un profesional del Derecho, en su vida diaria, participa en reuniones, audiencias, defensas orales, vistas, etc. Para ejercer con competencia su oficio, necesita, por tanto, no sólo del conocimiento jurídico sino también del dominio en el arte de defender sus exposiciones orales y el arte de escribir con técnica, exponiendo sus ideas con claridad y persuadiendo a su "oponente jurídico". Por tanto, debe dominar la teoría de la argumentación y de las técnicas argumentativas. Debe saber exteriorizar su pensamiento en palabras, en ideas ordenadas, con objetividad, concisión y método, exponiendo los hechos de forma clara y combinando conceptos y datos, con el objetivo de persuadir. La redacción del texto jurídico, reflejada en la teoría de la argumentación, constituye uno de los aspectos que debe integrar la gama de conocimiento del abogado para el buen ejercicio de su oficio $^{3}$.

La aplicación de principios, teorías y normas es habitual en la Política, en la Economía y, claro está, también en el Derecho. La norma jurídica no se puede aplicar de forma fría y literal al hecho que se está sometiendo a su consideración. El operador del Derecho debe buscar qué se esconde entre el significante y la significación explícita. No basta con la inclusión del hecho en el tipo legal, ni tampoco la subsunción. Basta apreciar que de la simple lectura de la Constitución o

\footnotetext{
${ }^{3}$ Una de las definiciones más claras que he encontrado sobre la argumentación jurídica es la propuesta por el profesor Francisco Puy Muñoz: "Una argumentación jurídica es un discurso por el que un jurista que ve claramente que una cosa es el derecho de una persona, ilumina esa realidad a otra u otras personas que no la ven en absoluto, o no la ven de una forma clara y precisa, y las convence de que actúen respetándolo. O bien, una argumentación jurídica es un discurso por el que un jurista que ve claramente la verdad de la tesis "esto pertenece a éste", explica, aclara o ilumina tal proposición a otra u otras personas que no entienden esa proposición de una forma clara y precisa, hasta que las persuade de que tal derecho existe y de que deben proceder respetándolo" (PUY MUÑOZ, F., "La expresión 'argumentación jurídica' y sinónimas. Un análisis tópico", en La argumentación jurídica. Problemas de concepto, método y aplicación. Edición de F. Puy Muñoz y J. Guillén Portela, Universidad de Santiago de Compostela, 2004, p.92). Este concepto abarca los significados descriptivos, estimativos y normativos de la expresión "argumentación jurídica" empleando el método tópico. Se desemboca así en la presentación de la argumentación jurídica como un discurso que reúne las condiciones más convenientes para que una persona que se cree titular de un derecho pueda persuadir a otra que se lo disputa de que se lo reconozca dentro de unos límites, se lo estime justo dentro de unos criterios, y se lo respete dentro de unas normas. Es una definición coherente con la propia forma que tiene el profesor Puy de relacionarse con el Derecho: ordenado, prudente, lógico, racional y, también pasional, y vehemente a la hora de defender aquello que considera imprescindible en el Derecho: la justicia.
}

REVISTA DO DIREITO UNISC, SANTA CRUZ DO SUL № $37 \mid$ p. 179-206| JAN-JUN 2012 
de un artículo de un Código, se abren múltiples posibilidades interpretativas al operador del Derecho.

En esta temática de la aplicabilidad se inserta el problema de la interpretación, el cual presupone un pensamiento hermenéutico vinculado a los casos concretos, ya que el Derecho, independientemente de sus instrumentos de positivación, que hacen positivos sus preceptos, y de cuáles fueren los valores que se sustenten, radica en lo social y se dirige de nuevo a lo social a la hora de aplicarse.

Al analizar un caso concreto es imposible eliminar los valores que sustentan la comprensión de los principios, ya que los factores que se colocan entre el texto y el intérprete o lector son innumerables, tanto de orden político, como social, cultural, antropológico o psicológico. Por ello, interpretar es poner en orden, es revelar el sentido de cada manifestación para insertarla en un sistema coherente.

Hay una opacidad del lenguaje que acaba haciendo difícil la cristalización del sentido puro del mismo. La multidireccionalidad del texto es irracional. Por ello, la racionalidad de la interpretación, a partir de un contexto pre-comprensivo es la que puede orientar adecuadamente su sentido.

La interpretación de la norma $e^{4}$, en el fondo, una cuestión de paradigma político-socio-económico del que deriva una infinidad de interpretaciones posiblemente válidas de un texto (escrito o hablado). La elección de una de ellas atiende al paradigma político-socio-económico del momento. Por tanto, decidimos la interpretación a partir de un contexto histórico, de pre-comprensión, de preconceptos del mundo y de la vida y de las condiciones del lenguaje, y por eso se afirma que es circunstancial e ideológica.

Toda interpretación se lleva a cabo en un contexto histórico, lo que presupone paradigmas y, para alcanzarlos, el ser humano no puede abstraerse de sí mismo

\footnotetext{
4 Hay numerosa bibliografía sobre la interpretación del Derecho. En lo que se refiere a la interpretación de las normas, podemos destacar, entre otros: GUASTINI, R., Estudios sobre la interpretación jurídica. México, UNAM, 1999; ATIENZA, M., Sobre la analogía en el derecho, Madrid, Civitas, 1986; CALVO GARCÍA, M. edtr., Interpretación y argumentación jurídica, Zaragoza, PUZ, 1995; EZQUIAGA GANUZAS, J., La argumentación en la Justicia Constitucional española, Oñate, IVAP, 1987; HASSEMER, W., "Hermenéutica y Derecho", Anales de la Cátedra Francisco Suárez 25, 1985, pp.63-85; OLLERO, A., Interpretación del derecho y positivismo legalista, Madrid, Edersa, 1982; PRIETO SANCHÍS, L., Ideología e interpretación jurídica, Madrid, Tecnos, 1987; SAAVEDRA, M., Interpretación del derecho y crítica jurídica, México, Fontamara, 1994; VERNENGO, R. J., La interpretación jurídica, México, UNAM, 1977.
} 
sino que debe de tener en cuenta la precomprensión usualmente dominante en la sociedad en la que actúa. Por ello, la pre-comprensión y la interpretación jurídica tiene un compromiso de cuño socio-histórico-ideológico y también de orden moral, ya que interpretar el Derecho es solucionar el caso concreto con la ayuda de un texto legal, de manera que se encuentre una decisión jurídicamente segura, socialmente aceptable y moralmente justa.

El Derecho es esencialmente lenguaje e interpretación, lo que permite afirmar que la práctica jurídica es una actividad en la que su especificidad viene determinada por la manera en cómo se sirve del lenguaje para poder influir en la complejidad de las relaciones sociales. El lenguaje es un proceso de interacción verbal y humana. Hay que reconocer el poder que la palabra ejerce sobre el otro y la complejidad del proceso persuasivo que, muchas veces, trasciende los límites del raciocinio lógico.

Las investigaciones sobre argumentación, especialmente las vinculadas a la retórica, han resaltado las formas mediante las cuales los sujetos, argumentando, convierten lo posible en necesario; lo permitido, en obligatorio; lo inaceptable en aceptable. El objetivo de la argumentación jurídica es pretender sustentar una tesis, de manera que cada tesis es susceptible de una antítesis, lo que determina que la elección de los argumentos aspiren a superar o minimizar la fragilidad de los sentidos del lenguaje y a reforzar los procedimientos de sustentación de la tesis, ya que la verdad de los argumentos es parcial.

\section{REVISITANDO LA TEORÍA DEL DISCURSO: DIALÉCTICA, RETÓRICA Y TÓPICA}

Como explica A. E. Pérez Luño, la argumentación jurídica es un tipo de razonamiento que, desde premisas verosímiles llega a conclusiones razonables. Se trata de un tipo de razonamiento concreto y adecuado al caso. Un ejemplo actual podemos encontrarlo en R. Alexy que sugiere reglas y procedimientos tendentes a garantizar la racionalidad de la argumentación jurídica. Se pretende evitar así que las valoraciones del jurista intérprete degeneren en juicios de valor subjetivos y 
arbitrarios. La referencia a las normas materiales y procesales aplicables al caso, la obligada consideración de los precedentes, así como las pautas orientadoras de la Dogmática jurídica, constituyen el horizonte en el que se proyecta la racionalidad práctica en el Derecho ${ }^{5}$.

Hasta llegar al modelo de argumentación jurídica que propone Alexy, ha habido un largo recorrido histórico. Analizar la argumentación jurídica nos remite necesariamente a sus raíces como son la Dialéctica, la Retórica y la Tópica, que tiene sus orígenes en la Grecia antigua. A la mayeútica socrática (método interrogativo de deslinde de una cuestión) le sucede la dialéctica de Platón (método más perfeccionado, basado en la opinión y crítica, pasando de concepto en concepto, de proposición en proposición, hasta alcanzar los conceptos más generales y los principios). Le sigue la Dialéctica de Aristóteles (contraposición sucesiva de opiniones, a partir de premisas colocadas intuitivamente), utilizando en el proceso la inducción y la deducción, con lo que nace la Lógica. Lógica deriva de logos (razón) y es el arte del raciocinio, del pensamiento coherente, integrando como método la filosofía. Para el estagirita, ciencia y prudencia son dos cosas diferentes. La prudencia es lo que conviene para un determinado fin, y de ahí porqué en su campo de aplicación (a asuntos generales) se aplican a la legislatura o a la jurisdicción. Baste recordar que la ciencia del derecho es tradicionalmente denominada "jurisprudencia" y no "jurisciencia".

A partir de aquí surgen tres ramas profundamente interrelacionadas: a) La dialéctica es el arte de la discusión bien organizada, el arte de discurrir o argumentar mediante problemas y contraposiciones; b) La organización de esa discusión compete a la Retórica, al arte de la elocuencia. Comprende clásicamente tres partes: la invención (búsqueda de argumentos, premisas, pruebas); la disposición (ordenación y encadenamiento de argumentos, pruebas, etc.); y la elocución (manera y forma de exponer que pretende llevar al convencimiento); c) La Tópica (de topos, topoi, puntos de vista): técnica dialéctica que estudia las conclusiones

\footnotetext{
${ }^{5}$ PÉREZ LUÑO, A.E., Lecciones de Filosofía del Derecho. Presupuestos para una Filosofía de la experiencia Jurídica. $2^{a}$ ed., Sevilla, Mergablum, p.109. Destaca Pérez Luño que entre los argumentos retóricos o esquemas de razonamiento tópico con mayor proyección jurídica pueden citarse los siguientes: a contrario, a simile, a fortiori y ad absurdum.
} 
extraídas de premisas aparentemente verdaderas, junto con opiniones respetadas y aceptadas $^{6}$.

En la época romana, Cicerón destacó por su aportación al ars disserendi (del discurso o de la argumentación), dividiéndolo en dos partes: tópica (descubrimiento o invención) y dialéctica (juicio sobre la prueba). Estableció un catálogo de tópicos, buscando lo que parezca mejor, de acuerdo con el conocimiento, la sabiduría y la experiencia. Los juriconsultos romanos trabajaron sobre la vida práctica, utilizando el "pensamiento sobre problemas" (aporías) de tipo dialéctico o argumentativo. Estos juriconsultos, junto con los jueces del commom law, también preferían el raciocinio problemático al sistemático.

También son relevantes las aportaciones de los pensadores de la antigüedad cristiana y del medievo, como San Ambrosio, San Agustín, San Isidoro de Sevilla y San Bonaventura. Santo Tomás de Aquino, seguidor de la teoría aristotélica, inclusive sobre el ars inveniendi (tópica), distingue la recta razón con respecto a las cosas prácticas (prudencia) de la recta razón especulativa (dirigida a la ciencia).

Como sostuvo Gian Battista Vico, en el inicio del siglo XVIII, hay dos métodos científicos: uno nuevo (crítica), cuyo desarrollo se produce de manera demostrativa, a través de largas cadenas deductivas, y otro antiguo (tópico-dialéctico), cuyo punto de partida es el sentido común, que trabaja lo verosímil, contrapone los topoi y utiliza una red de silogismos. Las ventajas del nuevo procedimiento serían la agudeza y la precisión; las desventajas, que predominan, consisten en una disminución de la visión prudente, atrofia de la fantasía, empobrecimiento del lenguaje y falta de maduración del juicio sobre asuntos humanos. Todo esto, según Vico, se puede evitar utilizando el antiguo método retórico y, especialmente, por su pieza esencial, la tópica retórica, que proporciona sabiduría, despierta la fantasía y la memoria y enseña cómo considerar un estado de cosas desde ángulos diversos. Por ello, se debe intercalar el método antiguo con el nuevo.

En la segunda mitad del siglo $\mathrm{XX}$, los teóricos del derecho se plantean la fórmula de administrar justicia desde la argumentación, sin olvidar el enfoque

\footnotetext{
${ }^{6}$ La Tópica es una de las seis obras aristotélicas reunidas en el Organon. La clasificación del estagirita en cuanto a los topoi se refiere a accidente, al género, a lo propio y a la definición, es decir, cuatro géneros que se relacionan con diez categorías (sustancia, cantidad, cualidad, relación, lugar, tiempo, estado, posición, acción y pasión). Los tópicos (loci communes) eran considerados así como puntos de vista utilizables y aceptables en cualquier parte.
}

REVISTA DO DIREITO UNISC, SANTA CRUZ DO SUL No $37 \mid$ p. 179-206| JAN-JUN 2012 
racional. El Tratado de la argumentación de Ch. Perelman o la Nueva filosofía de la interpretación del Derecho de Luis Recasens Siches, Theodor Viehweg, Gadamer y Chaim Perleman son algunos de los exponentes de las teorías de la argumentación en la actualidad. Así, Recasens sostiene que las normas jurídicas no pueden apreciarse bajo la óptica de su verdad o falsedad sino bajo el enfoque de otros valores, como los de la justicia, dignidad de la persona humana, libertad, igualdad, bien común, adecuación, eficacia, prudencia, etc. Esta axiología desemboca en una verdadera filosofía, no en la verdad de las ciencias empíricas ni en las de la lógica formal. La lógica de lo racional (matemático-física) no es un instrumento suficientemente apto para el delineamiento y la solución de los problemas humanos prácticos, como los políticos y los jurídicos pues no agota la totalidad del logos, no siendo más que una parte de la razón. Hay otras regiones, de diversa índole, que pertenecen a la razón entre ellas la lógica de lo razonable. Lo racional puro de la lógica de la inferencia es meramente explicativo; en cambio, el logos de lo razonable intenta comprender sentidos y nexos, realiza operaciones de valoración y establece finalidades. Por ello, resulta imposible estructurar el derecho positivo en un sistema de pura lógica deductiva; ningún conjunto de normas puede prever todas las contingencias humanas.

Entre los valores que inspiran al Derecho se encuentran aquellos fundamentales que dan lugar a criterios ideales de carácter universal -como los de la dignidad de la persona humana y los de libertad e igualdad-. Pero hay otra serie de valores que se podrían englobar en lo que tradicionalmente se llama prudencia y que merecen especial atención por parte del juez: congruencia histórica (adecuación al momento histórico); viabilidad de las normas jurídicas (que deben de aprobarse con vistas a la probabilidad de su real eficacia, de su real efectividad); ponderación de los efectos sobre el futuro inmediato que las leyes pueden llevar aparejados; armonía entre los diversos intereses legítimos contrapuestos, de manera que se satisfaga el mayor número posible de estos, con el mínimo de fricción social; legitimidad de los medios empleados para la consecución de los fines justos; respeto a las expectativas sociales; y otros muchos que se podrían citar siguiendo esta misma línea, ateniéndose al logos de lo humano, dirigido a los problemas concretos, evocados mediante los conceptos de sensatez, tino, discreción, cordura, 
ecuanimidad, equilibrio, circunspección, precaución, previsión, expeditividad, diligencia, plausabilidad, etc.

Ch. Perelman recupera el enfoque axiológico del derecho, basándose en la "teoría de los valores" presenta su teoría de la argumentación como una nueva retórica. La retórica aristotélica (estudio del discurso persuasivo) tenía dos límites: la evidencia, contra la cual no cabe argumentar, y la fuerza bruta, el poder coercitivo que impone sumisión. Entre ambos se encuentra el inmenso campo de la retórica, cuyo papel resulta indispensable en una concepción del derecho menos autoritaria y más democrática, que busca la paz judicial (el derecho no debe ser sólo obedecido sino también reconocido), siendo competencia del juez, como servidor del Estado de derecho, contribuir para la aceptación del sistema. Cada vez que un juez debe decidir si hubo falta, negligencia, imprudencia, cuando hay que precisar un patrón de conducta (actuar como "un buen padre de familia"), se acaba recurriendo a la idea de aquello que es o no razonable. Como afirma Perelman, lo razonable no remite a una solución única sino que implica una pluralidad de soluciones posibles; pero hay un límite para esa tolerancia que sería lo que no es aceptable, lo que resulta inadmisible en una comunidad en un momento dado. Lo inaceptable, lo que no tiene razón constituye un límite para cualquier formalismo en materia de derecho. De ahí porqué la teoría pura del derecho de Kelsen no da una explicación suficiente del funcionamiento efectivo del derecho, en la medida en que se empeña en separar el derecho del medio en el que el mismo funciona y de las relaciones sociales de ese medio.

Construyendo su teoría de la argumentación Perelman también distingue la demostración, típica de la lógica formal, que se asienta en un sistema de normas preestablecidas y prescinde de interlocutor para la validez de sus premisas, de la argumentación, que presupone un encuentro de mentes entre orador y auditorio o audiencia, pretendiendo la adhesión o el consenso. Tal proceso argumentativo se pauta mediante requisitos básicos (reglas acordadas, lenguaje común, finalidad de aceptación de una tesis, permeabilidad del auditorio, discurso compatible con la audiencia), instrumentos (hechos, verdades, presunciones, valores, jerarquías, lugares) y técnicas (asociación y disociación de ideas), estructurándose en parámetros de razonabilidad (aceptación social). Las nociones de orador, auditorio o 
audiencia, adhesión y consenso comprenden tanto la argumentación oral como la escrita.

A la aportación de Recasens, Perelman y Viehweg le seguirán otras como las de Stephen Toulmin, Neil MacCormick, Robert Alexy, Jürgen Habermas, y parte de la doctrina española que se ha interesado acerca de la teoría del discurso y de la argumentación jurídica ${ }^{7}$, aportando un fundamento filosófico a la superación de la lógica jurídico-formal de tinte cartesiano, introduciendo una renovada metodología en la interpretación del Derecho, rescatando el pensamiento clásico greco-romano, y preparan el reconocimiento, del consagrado principio general del derecho, de la razonabilidad-proporcionalidad, noción nunca apartada de la denominada "aplicación del Derecho" y claramente adoptada por la hermenéutica constitucional. La moderna interpretación constitucional, como proceso abierto de argumentación, se ayuda de la tópica. Esta, junto con la de la mediación, sería una vertiente interesante de reflexión, pero no queremos excedernos de los límites que nos hemos propuesto en este breve ensayo.

\section{ACUERDOS Y DESACUERDOS EN EL DERECHO}

Como bien sabemos, en las Facultades de Derecho se transmiten conocimientos acerca del Derecho y se enseñan habilidades y destrezas profesionales para que abogados, fiscales, jueces y demás operadores jurídicos sean capaces de predecir con razonable seguridad aquello que ocurrirá en un gran número de casos jurídicos. Sin embargo, la norma es general y los casos que acaecen en la vida real son muy variados y pocas veces se ajustan a la generalidad que la norma exige. Se producen así los acuerdos y desacuerdos en el significado jurídico ${ }^{8}$. Por ejemplo, en la entrada de un restaurante hay un cartel que exhibe "Se prohíbe entrar con perros". Pero, ¿y si se trata de una persona ciega que va

\footnotetext{
7 Vid. ATIENZA, M., Las razones del Derecho. Teoría de la argumentación jurídica. Madrid, CEC, 1991; del mismo autor, El Derecho como argumentación, Barcelona, Ariel, 2006; GASCÓN ABELLÁN, M., y GARCÍA FIGUEROA, A., La argumentación en el Derecho, Lima, Plestra, 2ª̣ed., 2005; como explicación de lo que han aportado estas teorías, vid. GARCíA AMADO, J.A., "Del método jurídico a las teorías de la argumentación", en AFD, 1986, pp.151-182; del mismo autor, "La teoría de la argumentación jurídica: logros y carencias", Revista de Ciencias Sociales, ㄲo45, 2000, pp.103-129.

En este punto, vamos a seguir a MORESO, J.J., PRIETO SANCHIS, L, y FERRER BELTRÁN, J., Los desacuerdos en el Derecho. Madrid, Fundación Coloquio Europeo, 2010.
}

REVISTA DO DIREITO UNISC, SANTA CRUZ DO SUL № 37|p. 179-206| JAN-JUN 2012 
acompañada de su perro guía? Esa prohibición ¿también contempla su circunstancia? Partiendo de un mismo enunciado "se prohíbe la entrada al restaurante con perros", su interpretación podría ser muy variada (en ningún caso, se puede entrar con perros, deberían existir excepciones, etc.).

Hay otros muchos casos en los que la discrepancia entre juristas es evidente. Por ejemplo, acerca de si la Constitución española autoriza o no el matrimonio entre personas del mismo sexo, o acerca de la interrupción del embarazo durante las primeras semanas. Incluso podríamos cuestionarnos si son desacuerdos jurídicos o si son sólo desacuerdos ideológicos disfrazados de un manto jurídico.

La presencia de los estándares morales ha sido una constante en toda experiencia jurídica: Orden público, Moral vigente, Diligencia de un buen padre de familia, Convivencia intolerable, Penas crueles y otros muchos. Ello desemboca en la "pesadilla" de quienes conciben el Derecho como una realidad radicalmente inconsistente e incompleta y del "noble sueño" de aquellos que prefieren imaginar el ordenamiento como un sistema cerrado y seguro. El Derecho reviste tientes morales -el propio lenguaje jurídico está impregnado de esos matices- y junto a las normas y reglas, en el Derecho hay estándares morales, principios y valores, que precisan de una interpretación al ahora de aplicarse. A su vez, la interpretación irá acompañada de una argumentación jurídica.

En este sentido podemos recordar la novela de Philip Kerr, Una investigación filosófica (Barcelona, Anagrama, 1996), en la que se describe el Londres de 2013 como una ciudad insegura con un alto grado de delincuencia. Entre las medidas que se toman para reducir esos niveles de inseguridad y delincuencia, se encuentra la imposición de un nuevo tipo de pena. Dado que la ciencia médica no ha conseguido inducir y revertir el estado de coma en los humanos, se sustituye la pena de prisión por el denominado coma punitivo. A los condenados a dicha pena se les induce el coma por el tiempo de la condena y son confinados en una especie de hospitales en donde no hay peligro de fugas ni de motines. Sólo hay que conservarlos con alimentación y respiración asistida. Las ventajas son claras, ya que ahorraría muchos gastos y problemas que conllevan los centros penitenciarios.

La normativa aplicable que podríamos citar para entender el planteamiento de la cuestión en sus debidas dimensiones sería: a) El artículo 5 de la Declaración Universal de Derechos Humanos de las Naciones Unidas de 1948: "nadie será REVISTA DO DIREITO UNISC, SANTA CRUZ DO SUL No $37 \mid$ p. 179-206| JAN-JUN 2012 
NURIA BELLOSO MARTÍN

sometido a torturas ni a penas o tratos inhumanos o degradantes"; b) El artículo 15 de la Constitución española -CE- que también prohíbe los tratos inhumanos o degradantes).

Si el coma punitivo se introdujera en el ordenamiento español: ¿sería esta una medida conforme con la Declaración Universal y la CE? ¿Cómo debe determinarse si el coma punitivo es o no un trato cruel, inhumano o degradante? Podemos plantear la solución desde dos teorías iusfilosóficas diversas: la neopositivista (H. Kelsen, H.L. Hart) ${ }^{9}$ y la Postpositivista (R. Dworkin) ${ }^{10}$ :

${ }^{9}$ El neopositivismo se debate entre dos posturas básicas: 1) El Positivismo débil inclusivo o incluyente (también conocido como incorporacionismo): afirma que es posible que la regla de reconocimiento de un sistema jurídico presente un carácter sustantivo, moral. El Derecho contemporáneo, con sus declaraciones de principios y valores morales contenidos en textos constitucionales, sólo puede explicarse adecuadamente admitiendo que en esos casos el Derecho recurre a la moralidad, es decir, que la moral puede determinar la existencia y el contenido del Derecho. L.A. Hart se opuso no sólo a las doctrinas del derecho natural, sino también al imperativismo de J. Austin, al trascendentalismo de $\mathrm{H}$. Kelsen y al empirismo de Alf Ross, al desvelarnos la importancia del "punto de vista interno" a la hora de estudiar el derecho. Con su distinción entre "verse obligado" a hacer algo y "tener la obligación" de hacerlo, Hart separa la filosofía jurídica de "ayer" de la de "hoy"; 2) El positivismo exclusivo (Joseph Raz): los llamados positivistas excluyentes mantienen que en ningún caso es condición de la validez jurídica de una norma su adecuación a la moralidad.

Según las corrientes anti-positivistas, los diversos sistemas jurídicos no sólo comparten rasgos formales, sino también ciertos rasgos sustantivos, singularmente, cierta adecuación a la moral racional. Con ello, el antipositivismo pretende ir más allá de un planteamiento positivista. Intenta dar respuesta a la intuición de que el Derecho parece responder a alguna dimensión moral. $R$. Dworkin se ha presentado como un claro no positivista (quizás el anti-positivista por antonomasia de las últimas décadas), sin asumir el aspecto de un iusnaturalista clásico. Nos encontramos con un no-positivista que no es iusnaturalista. (Vid. DWORKIN, R., La justicia con toga. Trad. de M. Iglesias Vila e I. Ortiz de Urbina Gimeno. Madrid, Marcial Pons, 2007).

${ }_{10}$ Dworkin no se limitó a examinar la forma como los principios entran en la práctica jurídica, en particular en la práctica de los tribunales, sino que los situó en el centro de una crítica frontal a la concepción del derecho que él mismo calificó como el "Modelo de reglas". Sus objeciones en este punto obligaron a revisar la concepción del sistema jurídico que había dominado la escena de la filosofía del derecho en las décadas inmediatamente anteriores, y que había sido elaborado en gran medida con ingredientes procedentes de la teoría del derecho de Kelsen y de Hart. En su obra Taking Rights Seriously (Los derechos en serio. Barcelona, Ariel, 1984) llamó la atención no sólo sobre los rasgos distintivos de los principios frente a las reglas, sino además sobre el modo como funcionan en los procesos de interpretación y argumentación jurídica. En su obra Law Empire (El imperio del Derecho, Fontana press, London 1986), esboza las líneas fundamentales de una teoría de la interpretación jurídica con el fin de ilustrar su tesis de que el derecho es fundamentalmente el producto de una práctica interpretativa y argumentativa.

Dworkin ha establecido una conexión entre los principios y los derechos, entendida como "triunfos". También ha articulado la distinción crucial entre principios, reglas y directrices políticas (policies) como modos diferenciados de manifestarse el poder normativo del Estado, sacando a la luz la estructura moral deontológica subyacente al complejo proceso de reproducción del sistema jurídico en un Estado constitucional democrático. Ha llamado la atención sobre el modo como las funciones de producción y de aplicación de las normas se encuentran en todos los niveles aunque de forma diferenciada, sujetas a principios de moralidad política. (Vid. las interesantes valoraciones del profesor A. E. Pérez Luño acerca de la aportación de R. Dworkin. PÉREZ LUÑO, Antonio Enrique, El desbordamiento de las fuentes del Derecho. Madrid, La Ley-Grupo Wolters Kluwer, 2001, pp.25-57).

REVISTA DO DIREITO UNISC, SANTA CRUZ DO SUL No $37 \mid$ p. 179-206| JAN-JUN 2012 
NURIA BELLOSO MARTÍN

a) Desde una perspectiva neopositivista: El derecho es un artefacto creado por los seres humanos y, como tal, imperfecto. Por ello, la coincidencia con la moralidad es contingente. La apelación a conceptos como el de tratos inhumanos o degradantes es confusa y, por tanto, el derecho español está indeterminado en todos los supuestos de aplicación de dicho concepto, con lo cual, los jueces gozan de discreción para resolver este caso. Si los juristas y jueces discrepan acerca de si el coma punitivo es o no un trato cruel, entonces los jueces tienen discreción en dichos casos.

b) Desde una perspectiva postpositivista: La Constitución debe ser interpretada del modo que favorezca en mayor medida fines preestablecidos. No pone tanto el énfasis en las intenciones de los constituyentes sino en las consecuencias de tomar una u otra vía interpretativa. El positivismo jurídico no puede dar cuenta de la pertenencia al derecho de estándares como los principios ${ }^{11}$, implícitos en la práctica aunque nadie los hubiera promulgado. Dworkin sostiene que el Derecho incorpora conceptos morales (como cuando prohíbe los tratos inhumanos y degradantes), por lo que los jueces deben aplicar el derecho siguiendo pautas morales. Es decir, la apelación a conceptos morales: a) para el neopositivismo representa la fuente principal de la discrecionalidad; para Dworkin es el fundamento

\footnotetext{
${ }^{11}$ R. Dworkin utiliza el conocido caso "Riggs versus Palmer" en el que el asesino alega que tiene derecho a heredar de su abuelo, la víctima. El testamento era válido y se redactó a favor del nieto asesino. Las reglas sobre sucesión testamentaria no incluían causas de indignidad para suceder, ni ninguna otra excepción. Pero el Tribunal decidió que la aplicación de las reglas jurídicas estaba sometida a los principios generales del Derecho, que incluía el principio de que "nadie debe aprovecharse de su propio delito". Decidieron que el nieto asesino, no tenía derecho a la herencia. Según Dworkin, este caso nos muestra que el Derecho no está formado exclusivamente por reglas puestas por el legislador (reglas de letras negras) sino que incluye principios. Los Principios se diferencian de las Reglas en una serie de aspectos: 1) Las reglas se aplican de un modo que es "todo o nada". Si una regla jurídica se aplica a un caso y es una regla válida, el caso tiene que decidirse de acuerdo con esta regla. Por ejemplo, un caso en el que se trate de un testamento que exige tres testigos mayores de edad. Por otra parte, un Principio da una razón para decidir el caso de una cierta manera, pero no da una razón concluyente. Un Principio puede ser un Principio jurídico vinculante, que es aplicable a un caso y, sin embargo, el caso no se decide, necesariamente, de acuerdo con este Principio. Esto se debe a que los Principios entran en conflicto unos con otros y deben sopesarse unos con otros. De todos modos, aunque la distinción es real, no es tan radical como piensa Dworkin. No todas las reglas son tan concluyentes como la citada; 2) Las reglas válidas no entran en conflicto. Si dos reglas jurídicas parece que entran en conflicto no pueden ser tratadas, las dos, como válidas. Los sistemas jurídicos suelen tener criterios para resolver estos problemas como, el criterio jerárquico, el cronológico y el de especialidad. Por otra parte, los Principios jurídicos pueden entrar en conflicto y seguir siendo, ambos, Principios jurídicos vinculantes; 3) Dado que los Principios pueden entrar en conflicto, los Principios jurídicos tienen una dimensión de "peso", que está ausente en las reglas jurídicas válidas. Es decir, las reglas jurídicas son válidas o inválidas pero no hay sopesamiento entre ellas. En cambio, los Principios deben ser sopesados, confrontados o balanceados unos contra otros, con el peso relativo que les atribuimos en cada caso concreto. De ahí que haya que "ponderar" los principios. Es decir, precisar sus condiciones de aplicación a un caso concreto.
}

REVISTA DO DIREITO UNISC, SANTA CRUZ DO SUL No $37 \mid$ p. 179-206| JAN-JUN 2012 
de la solución justa. Dworkin defiende principios abstractos tales como: Debido proceso, Dignidad humana, Libre desarrollo de la personalidad, Tratos crueles o degradantes.

Sin embargo, el problema y la dificultad estriba en cómo interpretar estos principios $^{12}$, en desacuerdos acerca del significado de "cruel", por ejemplo: La crueldad del coma punitivo no depende ni de lo que consideraban los constituyentes, ni de lo que considera ahora la sociedad, ni de lo que consideren los jueces del Tribunal Constitucional.

Los acuerdos y desacuerdos en la interpretación del Derecho no se producen únicamente por la presencia de estándares morales y de principios en el ordenamiento jurídico. En numerosas ocasiones, aclarar el significado de determinados conceptos es imprescindible para determinar qué norma se debe de aplicar y cómo hay que argumentar el caso.

Un primer ejemplo podemos encontrarlo en los tomates: ¿Son verduras o frutos? No es una aclaración baladí. Resultaba importante a la hora de aplicar un impuesto que gravaba la compraventa de verduras en Estados Unidos y que fue resuelto por el Tribunal Supremo en 1893.Concretamente, en 1833, en EE.UU. determinada legislación fiscal (Tariff Act of March 3, 1893) establecía una carga impositiva a la compraventa de verduras pero no a la de frutas. Se produjo una controversia acerca de si los tomates habían de ser clasificados como verduras o como frutos: a) Desde un punto de vista botánico, son un tipo de frutos; b) Desde un punto de vista culinario, acostumbramos a servir los tomates junto con otras verduras. Habría que concluir que son un fruto y que estaban exentos del impuesto. Sin embargo, la Corte Suprema de EE.UU sostuvo, por unanimidad que: Conforme al uso habitual de los términos y a los únicos efectos de la ley en disputa, los tomates son considerados verduras ${ }^{13}$.

Un segundo ejemplo que citan los autores es el de si los hongos son o no plantas alucinógenas. Había que averiguar si les es aplicable la legislación penal

\footnotetext{
${ }^{12}$ Vid. ÁVILA, H., Teoría de los principios. Trad. de I. Criado Sánchez. Madrid, Marcial Pons, 2011.

13 "Botánicamente hablando, los tomates son el fruto de una planta, como lo son los pepinos, los calabacines, las judías y los guisantes. Pero en el lenguaje común de la gente, sea de los vendedores o consumidores de estos productos, todos son verduras que se cultivan en los huertos domésticos y que cocinados o crudos, son como las patatas, zanahorias, nabos, remolacha o coliflor, la col, apio o lechuga, que usualmente se sirven para cenar o después de al sopa, el pescado o la carne que constituye la parte principal de la comida y no, como los frutos generalmente, el postre". (MORESO, J.J., PRIETO SANCHIS, L, y FERRER BELTRÁN, J., Los desacuerdos en el Derecho, cit.).
}

REVISTA DO DIREITO UNISC, SANTA CRUZ DO SUL No $37 \mid$ p. 179-206| JAN-JUN 2012 
NURIA BELLOSO MARTÍN

que prohíbe traficar con dichas sustancias según el código penal alemán. El caso fue resuelto por el Tribunal Supremo Federal de Alemania en 2007. La legislación penal, la ley de tráfico de estupefacientes -que contiene un anexo con las sustancias prohibidas- alemana castigaba el tráfico de plantas alucinógenas. Algunos de los defensores de traficantes con hongos alucinógenos arguyeron que los hongos no son, botánicamente, plantas, por lo que no podían ser penados por su tráfico y conforme a ello el Tribunal Superior de Coblenza absolvió a unos acusados de este delito. Sin embargo, en octubre de 2006, el Tribunal Supremo Federal de Alemania, revoca en casación esta decisión con argumentos similares a los que 100 años antes había utilizado el Tribunal Supremo estadounidense ${ }^{14}$.

Un tercer ejemplo podemos encontrarlo en el ejemplo del caso de "asesino nato" y el necesario recurso a la ponderación ${ }^{15}$, cuando se produce una colisión entre derechos fundamentales. Recurrimos a un ejemplo que R. Alexy ha utilizado en diversas ocasiones -también utilizado por C. Bernal Pulido-. Es un caso de colisión entre la libertad de expresión y el derecho al honor en el cual la revista satírica Titanic había llamado 'asesino nato' y, en otra edición posterior, 'tullido' a un oficial de la reserva que era parapléjico y que había logrado ser llamado de nuevo a filas para llevar a cabo unos ejercicios militares. C. Bernal analiza cómo las técnicas

\footnotetext{
14 "En verdad se reconoce en la biología que los hongos se ubican como un grupo independiente de organismos junto a las plantas (verdes) [...] en definitiva, se compran generalmente hongos también en fruterías y verdulerías. La filiación [entre plantas y hongos] es comprobada mediante una búsqueda en Internet [...]. Precisamente allí pueden encontrarse algunas páginas webs en las que se indica que los hongos - desde un punto de vista científico- no son como las plantas, aunque también allí se añade que los hongos siempre son clasificados de manera errónea (en el lenguaje ordinario) a las plantas.
}

${ }^{15}$ Las colisiones entre principios han de ser resueltas, según R. Alexy, de modo distinto a la colisión entre reglas. Cuando dos principios entran en colisión (por ejemplo, porque el primero establece que una conducta determinada está prohibida y el segundo que está permitida) uno de los dos ha de ceder frente al otro. Pero esto no significa que uno de los dos principios sea inválido, ni que en el principio desplazado haya que introducir alguna excepción. Lo que sucede es que. en determinadas circunstancias, un principio precede al otro. Es por esta razón que se afirma que, en los casos concretos, los principios tienen diferente peso y el conflicto ha de resolverse según la dimensión de peso y no según la dimensión de validez. La dimensión de peso, entonces, configura el núcleo de la ponderación. Dicha operación forma parte de lo que es requerido por un principio más comprensivo: el principio de proporcionalidad. Este principio comprende tres subprincipios: a) el principio de adecuación, es decir, que el sacrificio impuesto en el ejercicio de un derecho sea adecuado para preservar otro derecho o un bien constitucionalmente protegido, b) el principio de necesidad, esto es, que el sacrificio impuesto sea necesario -que no exista otro menos lesivo- para preservar otro derecho o un bien constitucionalmente protegido, y c) el principio de proporcionalidad en sentido estricto, en donde la ponderación propiamente dicha ocupa su lugar, que se afecte al ejercicio del derecho en el menor grado posible compatible con la mayor satisfacción en el ejercicio del otro derecho (MORESO, J.J., "Alexy y la aritmética de la ponderación", en M. Carbonell (Compil.), Argumentación jurídica. El juicio de ponderación. México, Porrúa, 2012.

REVISTA DO DIREITO UNISC, SANTA CRUZ DO SUL No $37 \mid$ p. 179-206| JAN-JUN 2012 
de la interpretación, ni los "metacriterios" de solución de antinomias sirven para resolver el caso y la única estrategia para la resolución del conflicto entre derecho al honor y la libertad de información es la ponderación. Recurrir a los criterios interpretativos habituales (lógico, sistemático y gramatical) no permitía encontrar la solución. Los criterios entre reglas se pueden solucionar acudiendo a los criterios de jerarquía, temporalidad y especificación. Pero ¿qué sucede cuándo los que entran en colisión no son reglas sino principios? Aquí se hace necesario acudir a la ponderación, en la que habrá que tomar en consideración la condición de precedencia condicional de acuerdo con las circunstancias concretas del caso ${ }^{16}$.

El Tribunal Superior de Dusseldorf condenó a la revista a pagar una indemnización de 12.000 marcos alemanes al oficial. La revista interpuso un recurso de amparo y, de acuerdo con la reconstrucción de Alexy, el Tribunal Constitucional consideró que mientras llamar al oficial 'asesino nato' era una interferencia moderada o leve en su derecho al honor, porque este tipo de apelativos eran usuales en su estilo satírico, en cambio la interferencia en la libertad de expresión se considera grave; llamar 'tullido' a un parapléjico se considera una interferencia gravísima que derrota la interferencia grave en la libertad de expresión de la revista. Es decir, que por este segundo apelativo únicamente estimó el Tribunal el recurso de amparo.

J.J. Moreso subraya que esta sentencia también muestra claramente la dificultad de establecer criterios generales con el método de la ponderación: en el caso de la expresión 'asesino nato" la libertad de expresión precede al derecho al honor, en el caso de 'tullido' ocurre lo contrario y se da primacía al derecho al honor sobre la libertad de expresión. ¿Qué sucederá, entonces, en otro supuesto de expresión denigratoria en el futuro? ¿Puede alguien decirlo con seguridad ${ }^{17}$

\footnotetext{
${ }^{16}$ BERNAL PULIDO, C., "Los Derechos fundamentales y la teoría de los principios. ¿Es la teoría de los principios la base para una Teoría adecuada de los Derechos fundamentales de la Constitución española? En DOXA, no130, 2007, pp.273-291; vid. también, ALEXY, Robert, "Derechos fundamentales, ponderación y racionalidad", Revista Iberoamericana de Derecho Procesal, enero - junio de 2009, pp. 3 -14.

${ }_{17}$ Por estas razones, Moreso sostiene que es mejor pensar en un modo de configurar la ponderación que la considera un paso previo a la subsunción. Una vía según la cual la ponderación es únicamente la operación que permite pasar de las normas que establecen derechos fundamentales, que tienen la estructura de principios -pautas con las condiciones de aplicación abiertas-, a reglas -pautas con las condiciones de aplicación clausuradas-, con las cuales es posible llevar a cabo la subsunción, en el ámbito de un problema normativo determinado.
}

REVISTA DO DIREITO UNISC, SANTA CRUZ DO SUL № 37| p. 179-206| JAN-JUN 2012 
Todas estas apreciaciones nos permiten entender que la práctica jurídica está llena de apreciaciones personales del que juzga, de valoraciones subjetivas y, consiguientemente, de decisiones propiamente dichas, de opciones entre alternativas. Por mucho que el legislador se esfuerce, la complejidad de los hechos es inaprensible en el lenguaje de las normas jurídicas. Los enunciados legislativos acotan espacios dentro de los que las decisiones han de moverse, pero no son capaces de determinar éstas al cien por cien. Con los hechos pasa otro tanto y el juez generalmente no se limita a constatar con certeza plena, con seguridad absoluta, si un hecho aconteció o no, sino que ha de valorar pruebas más o menos claras, indicios algo dudosos, testimonios contradictorios, concatenaciones fácticas meramente probables, etc. Así pues, quien en Derecho juzga ha de valorar, esas valoraciones tienen un componente personal, subjetivo, y se trata de saber si con ello campa por sus respetos la arbitrariedad en las práctica judicial -o decisoria en general en Derecho- o si hay manera de controlar esas valoraciones para que sean razonables en su contenido, asumibles en sus efectos y practicadas con buena fe y sin corruptelas ni inconfesables intenciones.

Las posiciones ante la argumentación jurídica han sido variadas a lo largo de la historia:

a) En primer lugar, en el siglo XIX, dominado por la corriente del Positivismo jurídico, no se presentaban muchos problemas ya que el Derecho estaba todo en los códigos, completo, acabado y claro, y el juez no tenía más que conocerlo, sólo debía averiguar la recta solución que para cada caso en la letra de la ley se predeterminaba por completo. Se trabajaba con la subsunción. Esta metodología se proyecta en el neopositivismo de Hart $^{18}$.

Para Moreso, hay dos reglas indiscutibles: R1: Las informaciones de relevancia pública, veraces y no injuriosas están permitidas; R2: Las informaciones que no son de relevancia pública o carecen de veracidad o son injuriosas están prohibidas y, en el caso que se produzcan, generan un derecho a ser indemnizado.

${ }^{18}$ Hart ha expuesto claramente las tres tesis del positivismo jurídico, en un trabajo publicado en español (HART, H.L.A., "El nuevo desafío del positivismo jurídico", en Sistema, no36, trad. de F. Laporta, L. Hierro y J.R. del Páramo, 1990, pp.3-19. Este texto es el resultado de una conferencia impartida por Hart en la Universidad Autónoma de Madrid, el día 29 de octubre de 1979. Vid. también, SCHIAVELLO, A., II positivismo giuridico dopo Herbert L.H. Hart: un'introduzione critica. Torino, G. Giappiechelli, 2002). La primera, es la que denomina la tesis de la Separación Conceptual del derecho y de la moral. Argumenta que, a pesar de que existan numerosas e importantes conexiones entre derecho y moral, de modo que frecuentemente hay una coincidencia o solapamiento "de hecho" entre el derecho de algún sistema y las exigencias de moralidad, tales conexiones son contingentes, 
El positivismo jurídico formalista sustenta el siguiente ideario:

1.Creencia en el sistema jurídico como algo esencialmente completo y omnicomprensivo

2.Creencia en la separación de poderes y en la distinción creación/aplicación del Derecho como algo inherente a todo Derecho.

3.Creencia en que el legislador debe armonizar el nuevo Derecho con el preexistente.

4.Creencia en el derecho en los libros (frente al Derecho en acción)

5.Creencia en que la abstracción y geneneralidad son virtudes del Derecho

6.Creencia en una lógica interna del Derecho

7.Creencia en la teoría de la subsunción o del silogismo en la aplicación del Derecho

8.Creencia en la certeza y predecibilidad como ideales jurídicos

Los positivistas formalistas tienen preferencia por las reglas que puedan aplicar a plena satisfacción de la séptima de las creencias formalistas indicadas.

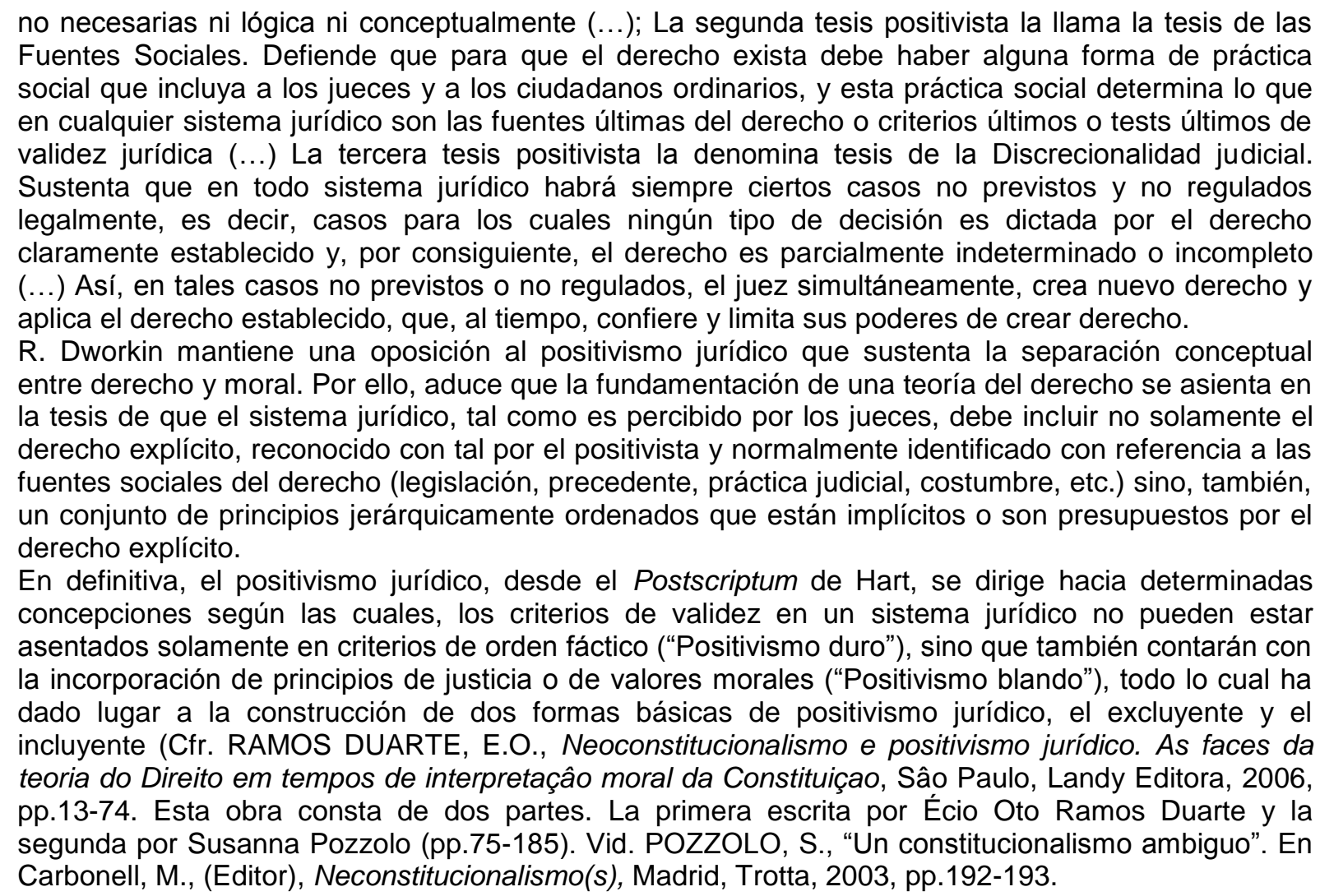
No $37 \mid$ p. 179-206| JAN-JUN 2012 
b) En segundo lugar, por su parte, los neconstitucionalistas ${ }^{19}$, inspirándose en la teoría de Dworkin, tienen el siguiente ideario:

1) Más principios que reglas

2) Más ponderación que subsunción

3) Omnipresencia de la Constitución en todas las áreas jurídicas y en todos los conflictos meramente relevantes, en lugar de espacio dejados a la opción legislativa o reglamentaria;

4) Omnipotencia judicial en lugar de autonomía del legislador o reglamentaria

5) Coexistencia de una constelación de valores, a veces tendencialmente contradictorios, en lugar de homogeneidad ideológica en torno a un puñado de principios coherentes entre sí y en torno, principalmente, a las sucesivas opciones legislativas.

c) En tercer y último lugar, el Realismo jurídico americano y escandinavo sostiene que no hay propiamente más Derecho que lo que manda el juez. Aquel margen decisorio que el juez tiene no es acotado, sino pleno y que en él no ejerce el juez libertad, sino puro libertinaje. No hay quien sea capaz de limitar la arbitrariedad de los jueces, pues ellos tienen la última palabra. Códigos y reglamentos son letra muerta y papel mojado. Quien haya de ganar un pleito se deje de invocar preceptos, adagios, principios o precedentes y se ocupe de ver cuál es la ideología del juez.

\section{LA ARGUMENTACIÓN JURÍDICA EN EL PROCESO JUDICIAL}

La fórmula básica utilizada desde la antigüedad por los abogados en el ejercicio de su profesión incluye: analizar, dictaminar, persuadir, justificar y convencer para influir en la decisión del juez.

Convencer al cliente o al juez obliga al abogado a practicar el arte de la persuasión y ello, en detrimento de lo que la interpretación formal considera la verdadera demostración, la que conduce a la certeza de la ley. El objetivo del discurso del abogado defensor es tratar los sentimientos de la audiencia y conseguir que se le crea y se decida a su favor. El que quiere convencer tiene que pensar los conceptos destinados a demostrar lo que se propone y comunicar las

19 Vid. COMANDUCCI, P., AHUMAdA, Mạ.A., y GONZÁLEZ LAGIER, D., Positivismo jurídico y neconstitucionalismo. Madrid, Fundación Coloquio Jurídico Europeo.

REVISTA DO DIREITO UNISC, SANTA CRUZ DO SUL No $37 \mid$ p. 179-206| JAN-JUN 2012 
razones para probarlo. La dificultad de la argumentación es de carácter intelectual porque consiste en usar el pensamiento para razonar.

El abogado debe saber en qué momento adecuado debe utilizar el discurso, el diálogo y el debate y con qué interlocutor (cliente, juez) debe utilizarlas. La acción comunicativa que el profesional del derecho vaya a utilizar en cada asunto dependerá del grado de defensibilidad que éste requiera, en función de si es un caso fácil, o un caso de duda seria o un caso de causa oscura $u$ otros ${ }^{20}$.

Un conflicto no sólo implica un hecho con su correcta definición sino que también hay que tener presente su proceso, circunstancia o relación con otros hechos. Un conflicto implica, además y sobre todo, las diversas valoraciones que se dan acerca de ese hecho.

La argumentación jurídica no sólo se exige para el abogado defensor de una causa o para el fiscal de la acusación, también el juez debe de argumentar su decisión, su sentencia. El juez posee márgenes decisorios, espacios en los que libremente campa su valoración pues ni los hechos hablan por sí mismos con rotundidad que excluya toda duda ni las normas están escritas en un lenguaje unívoco que haga ociosa la interpretación ni, por supuesto, es verdad que el Derecho sea coherente, completo y claro gracias a que donde no llega la letra de la ley alcanza el espíritu del legislador y, donde éste no sea bueno, todo lo solventan unos valores que a la vez son morales y jurídicos sin dejar, además, de ser un misterio insondable, pues todos los afirman pero cada cual los rellena para cada caso del contenido como considere oportuno.

El juez tiene que decidir libremente dentro de ciertos márgenes acotados por lo que en las normas y en los hechos esté claro, el sentido común, la lógica y por el

20 El cine -interesante instrumento docente para los cursos jurídicos- proporciona numerosos ejemplos de cómo el abogado desarrolla una brillante argumentación jurídica: Anatomy of a morder (Estados Unidos, 1959. Dirección: Otto Preminger); A civil Action (Estados Unidos, 1998. Dirección: Steven Zaillian), Witness for the prossecution (Estados Unidos, 1957. Dirección Billy Wilder. Destacamos el Abogado sarcástico y brillante -Sir Wilfrid Roberts- (Sir Charles Laughton)-. Sobre Derecho y cine recomendamos: RIVAYA, B. y DE CIMA, P., Derecho y Cine en 100 películas. Una guía básica, Valencia, Tirant lo Blanch, 2004; también, SAN MIGUEL, E., "Justicia, derecho y cine. Una antología”, en Varios, Abogados de cine. Leyes y juicios en la pantalla, Madrid, Castalia y Colegio de Abogados de Madrid, 1996, p. 137-145; y, también, SOTO NIETO, F. y FERNÁNDEZ, F.J., Imágenes y justicia. El Derecho a través del cine. Madrid, La Ley, 2004. 
estado de la ciencia (acotados, sí, pero no completamente y libertad limitada, sí, pero libertad) $)^{21}$.

Por eso exigimos al juez que argumente. No nos basta con que decida porque le compete sino que se le pide que dé cuenta de por qué decidió así y no de algún otro modo de los posibles, de los que caen dentro de aquellos márgenes acotados. $A$ ese dar cuenta de sus razones para fallar así o de otra manera se llama motivar y por eso se dice que las sentencias tienen que estar motivadas (art. 120 de la CE). Esta argumentación por parte del juez implica que debe motivar la sentencia. Es decir, motivar o justificar una decisión judicial "consiste en intentar convencer o persuadir a los ciudadanos (o a un determinado público o auditorio) a fin de que acepten la decisión; o en intentar mostrar que la decisión es justa, o razonable, o que tiene

${ }^{21}$ Sobre las decisiones judiciales y la motivación judicial hay numerosa bibliografía. Destacamos: REDONDO, Mà.C., SAUCA, J.Mํ.., y ANDRÉS IBÁNEZ; Estado de Derecho y decisiones judiciales. Madrid, Fundación Coloquio Jurídico Europeo, 2009; IGARTUA SALAVERRIA, J., Discrecionalidad técnica, motivación y control jurisdiccional. Madrid, Civitas, 1998; GASCÓN ABELLÁN, M., La técnica del precedente y la argumentación racional. Madrid, Tecnos, 1993; también, de la misma autora, Los hechos en el Derecho. Bases argumentales de la prueba. $3^{\mathrm{a}}$ ed., Madrid, Marcial Pons, 2010; RODRÍGUEZ CALERO, J.M., Principios del Derecho y razonamiento jurídico. Madrid, Dykinson, 2004; POSNER, R.A., Cómo deciden los jueces. Madrid, Marcial Pons, 2011. Sobre la estructura lógica de las sentencias judiciales, vid. CHIASSONI, P.L., Técnicas de interpretación jurídica. Breviario para juristas. Trad. de P. Luque Sánchez y M. Narváez Mora. Madrid, Marcial Pons, 2011; GARCíA AMADO, J.A., "Sobre el precedente judicial como argumento y como norma", en M. Otero Parga, (Coordinadora), en Tópica, Retórica y Dialéctica en la jurisprudencia, Ed. Universidad de Santiago de Compostela, Santiago, 2011, pp.153-162; tambien, LAMSDORFF-GALAGANE, V., "Sobre el razonamiento de los jueces", en M. Otero Parga, (Coordinadora), en Tópica, Retórica y Dialéctica en la jurisprudencia, Ed. Universidad de Santiago de Compostela, Santiago, 2011, pp.209-218. En cuanto al tema de la prueba, destacamos: TARUFFO, M., La prueba. Trad. de L. Manríquez y J. Ferrer Beltrán. Madrid, Marcial Pons, 2008.

REVISTA DO DIREITO UNISC, SANTA CRUZ DO SUL No $37 \mid$ p. 179-206| JAN-JUN 2012 
consecuencias deseables"22 La motivación ha de ser suficiente, completa y correcta conforme al derecho, como sostiene R. de Asís Roig ${ }^{23}$.

El juez ha de argumentar sus decisiones: debe presentarlas como las que en su lugar podría haber tomado cualquier persona capaz, informada y razonable y, principalmente, honesta. De esa manera está tratando de alejar la sospecha de que lo guía el capricho o el interés personal, o que decidió lanzando una moneda al aire. No nos basta con resultados, necesitamos también razones ${ }^{24}$.

\section{COMUNICACIÓN Y ARGUMENTACIÓN: MEDIACIÓN VERSUS PROCESO JUDICIAL}

Aristóteles, autor del primer tratado de la tópica general que conocemos, comenzó su obra con estas palabras: "En este tratado me propongo encontrar un método que habilite al que lo use para razonar, partiendo de opiniones que sean generalmente admitidas, acerca de cualquier problema que se le proponga, y que le capacite así mismo, cuando esté defendiendo un argumento, para evitar decir algo que pueda estorbárselo". Al compás de las reflexiones que, sobre la teoría de la argumentación estamos exponiendo ${ }^{25}$, nos surge la duda de cómo se podría aplicar

22 HERNÁNDEZ MARíN, R., Las obligaciones básicas de los jueces. Madrid, Marcial Pons, 2005, p.144. "La motivación de una decisión judicial contiene (entre otras cosas) un relato sumario, realizado por el juez, de lo que dicen los escritos de las partes y del resultado de las pruebas practicadas. Cuando la Resolución judicial que contiene ese relato es publicada, un ciudadano cualquiera puede conocer, a través de ese relato, parte al menos de los hechos que han originado el litigio. Es una vía muy indirecta e insuficiente para conocer estos hechos, ya que éstos son filtrados a través del relato judicial (el cual a su vez está mediado por la documentación integrante de los autos) y el relato no pretende realizar una descripción de dichos hechos, ni siquiera indirecta, que sea lo más completa posible. Pero un ciudadano corriente no dispone de otros medios más directos, ni más completos, ni más accesibles, ni más fiables para conocer esos hechos. Si las decisiones no fueran motivadas o las motivaciones de las decisiones no fueran publicadas, sería muy difícil para un ciudadano normal conocer lo más mínimo de los hechos que han originado el litigio. Y no sólo los hechos: tampoco sería posible conocer qué enunciado jurídico ha sido (presuntamente, al menos) aplicado por una decisión. Y sin conocer los hechos ni el derecho (presuntamente) aplicado es imposible saber si una decisión es materialmente correcta. Pero la corrección material de una decisión no depende de que se sepa que la decisión es correcta, ni de que la decisión sea motivada, ni tampoco de que sea publicada la motivación de la decisión (Ibidem, pp.147-148).

${ }^{23}$ De ASíS ROIG, R., Sobre el razonamiento judicial, Madrid, McGrawHill, 1998; también, del mismo autor, El juez y la motivación en el Derecho. Madrid, Dykinson, 2005.

${ }^{24}$ Recurriendo una vez más al cine, recordamos la brillante argumentación, por parte del juez Haywood, en la película Judgment at Nuremberg (Estados Unidos, 1961. Dirección: Stanley Kramer).

${ }^{25} \mathrm{~F}$. Puy ha constituido un exponente de la defensa de la tópica jurídica en sus diversas vertientes (tópica jurídica doctrinal, legal, judicial, historiográfica, mítica y teológica, literaria y mediática) La tópica jurídica es un repertorio de lugares comunes u opiniones compartidas. Y también es el arte de buscar ahí tópicos, y de argumentar con ellos, y de convencer y disuadir con ellos, y de motivar la 
todo esto al contexto de un procedimiento de mediación ${ }^{26}$. Es decir, en la mediación partimos de varias premisas: a) hay varias partes en conflicto; b) el mediador no da la solución sino que ayuda a las partes a gestionar su conflicto; c) La comunicación es el elemento esencial para que las partes en conflicto y el mediador gestionen el conflicto; d) Son las partes quienes deciden cómo gestionar y, si es el caso, resolver su conflicto.

La mediación eficaz depende de factores muy diversos como el grado de hostilidad entre las partes, la cantidad de recursos disponibles para distribuirse entre las partes, la existencia de "principios" que impliquen a las partes, la relación de poder entre esas partes implicadas, etc. Sin embargo, y a pesar de todos estos aspectos contingentes a la eficacia de las conductas de mediación, se puede apreciar la relevancia de determinadas técnicas que tienden a favorecer la creación de un buen clima que permita a las partes dirimir sus diferencias. Entre estas técnicas y habilidades típicas de la comunicación en mediación, cabe destacar: a) escucha activa empática; b) reenmarcación de frases negativas; c) realizar preguntas; d) equilibrar el poder; e) gestionar la ira y las emociones fuertes; g) Resolver el estancamiento con intervenciones; h) Velar por la eficacia de los resultados del proceso.

No podemos extendernos en el análisis de los modelos teóricos de mediación (modelo Harvard, modelo circular narrativo, modelo trasformativos o modelo tópico) que, sin duda, determinan a su vez la acción comunicacional y la forma de

acción pacificadora de los involucrados en un conflicto, después que se produjo, o antes de que se produjera (normalmente, en sus primeras escaramuzas). Y también es, aunque ya menos, la teoría que sistematiza, en cualquier aspecto la confección del repertorio o el arte de usarlo. Y también es, en fin, el método de trabajo más adecuado para todo ello, por estar pensado para lo que sea. Todo ello es la tópica. Todo ello forma un continuo. Pero parece claro que el paso crucial de ese conjunto está en el arte. Por lo tanto, la tópica jurídica consiste sobre todo en ser un arte, una técnica jurídica (PUY Muñoz, F. y LÓPEZ MORENO, A., Coordinadores), Manual de Filosofía del Derecho, Madrid, Colex, 2000, p.423. Vid. PUY MUÑOZ, F., 'La expresión 'mediación jurídica': un análisis tópico, en Soleto Muñoz, H., y Otero Parga, M., (Coordinadoras), Mediación y solución de conflictos, Madrid, Tecnos, 2007, pp.21-35; en la misma obra, OTERO PARGA, M., "Ventajas e inconvenientes de la mediación", op.cit., pp.144-157; también, BELLOSO MARTíN, N. (Coordinadora), Estudios sobre mediación: La Ley de mediación familiar de Castilla y León, Consejería de Familia e Igualdad de Oportunidades de la Junta de Castilla y León, Valladolid, Indipress, 2006.

${ }^{26}$ Vid. PUY MUÑOZ, F., "La expresión 'mediación jurídica': un análisis tópico, en Soleto Muñoz, H., y Otero Parga, M., (Coordinadoras), Mediación y solución de conflictos, Madrid, Tecnos, 2007, pp.2135; en la misma obra, OTERO PARGA, M., "Ventajas e inconvenientes de la mediación", op.cit., pp.144-157; también, BELLOSO MARTíN, N. (Coordinadora), Estudios sobre mediación: La Ley de mediación familiar de Castilla y León, Consejería de Familia e Igualdad de Oportunidades de la Junta de Castilla y León, Valladolid, Indipress, 2006.

REVISTA DO DIREITO UNISC, SANTA CRUZ DO SUL № $37 \mid$ p. 179-206| JAN-JUN 2012 
argumentar, dependiendo del modelo que se siga en un procedimiento de mediación. El mediador no debe de intentar convencer o persuadir a ninguna de las partes en conflicto; su argumentación va a ir por otros derroteros que no son el merco convencimiento; no debe ser negativo. Concretamente, su comunicación debe desarrollarse respetando estos parámetros ${ }^{27}$ :

-Permanecer activo y asertivo mediante el control del proceso;

- Establecer el tono afectivo de la mediación, basándose fundamentalmente en la paráfrasis y la reenmarcación;

- Escuchar a cada una de las partes, hacer preguntas, inducir y sintetizar;

- Proteger el derecho de las partes a participar y exponer sus opiniones;

- Ayudar a liberar tensiones y emociones para facilitar el diálogo entre las partes;

- Orientar a las partes a centrarse en el futuro y no ampararse en el pasado;

- Empujarles a una solución, animándoles a analizar las alternativas e implicándoles en su definición;

- Cultivar el sentido del humor;

- Velar por la eficacia de los resultados;

- Conocer y asumir las limitaciones de la mediación;

En la mediación, como pueda ser la mediación familiar, por ejemplo, se pueden utilizar unos mapas de fases. Los participantes proponen estructuras al describir un tópico utilizando cualidades específicas como factuales, de interés, de valor o relacional. Cuando las partes en conflicto adoptan a misma estructura, surge una fase de interacción consistente en la cual las partes se concentraban en aspectos específicos de cuestiones fundamentales, como pensión o visitas. Por otro lado, si las otras partes rechazaban las estructuras propuestas, eso frecuentemente desencadena un periodo nulo, en el cual no se resuelven las cuestiones y la comunicación resulta desorganizada, ya que los hablantes transitan de una estructura para otra, sin orden ni concierto.

Generalmente, los disputantes en conflicto parecen escoger una estructura dominante para expresar sus cuestiones en disputa. La estructura que generalmente

\footnotetext{
${ }^{27}$ BUTTS GRIGGS, T., MUNDUATE, L., BARÓN, M. y MEDINA, F., "Intervenciones de mediación", en Gestión del conflicto, negociación y mediación, L. Munduate Jaca y F.J. Medina Díaz (Coordinadores), Madrid, Pirámide, 2006, p.280.
} 
domina es la factual. La convergencia de estructuras parece estar asociada a la capacidad de los disputantes de alcanzar acuerdos fundamentales en su conflicto. Si se comunican dentro de estructuras convergentes, su capacidad de sellar acuerdos aumenta. De ahí que en la mediación resulte importante comprender la teoría de estructuración comunicativa, debiendo los mediadores prestar atención a las habilidades de estructuración. El control del mediador o del negociador lleva a los disputantes en dirección a una resolución integradora o los aleja de la misma. El mediador es el encargado de dirigir la convergencia de estructuras, de equilibrar el poder y de organizar la comunicación.

Ahora bien, si se trata de un proceso judicial, el rol que desempeña el mediador como neutral e imparcial, desaparecería, ya que un abogado aconseja las partes, le asesora sobre qué opción debe elegir o cuál rechazar. Es decir, el sistema de comunicación se altera profundamente. La misión del abogado ${ }^{28}$ es defender a su cliente argumentando sus valoraciones de los hechos como preferibles a las contrarias. La argumentación que vaya a utilizar el abogado transita por una estructura (la comunicación), tiene un contenido (argumentaciones) y toma una forma (lenguaje). Si el abogado quiere argumentar de manera metódica y eficaz no puede prescindir del buen uso de las reglas de la comunicación y de la estrategia comunicativa a que dan lugar sus tres vías de solución: discurso, diálogo y debate. A la habilidad de la retórica (comunicación) del profesional del derecho hay que sumar la dialéctica (argumentación) y la oratoria (lenguaje). Los problemas o conflictos que trata el abogado giran en torno a las diferentes valoraciones de los hechos. Sus argumentaciones serán de carácter legal pero antes son de carácter racional. Unas serán buenas razones, otras tendrán un sustento más débil o incluso, falso o equivocado. El mayor o menor éxito de su argumentación dependerá del carácter riguroso de su argumentación y de su hábil aplicación a la misma.

Entre las diversas cuestiones que se esperan del profesional del derecho se encuentra la de convertir los "intereses" particulares de su cliente en "valores" razonables que se puedan argumentar ante el juez. En la argumentación jurídica, como ya apuntaron Quintiliano y Cicerón, se dan dos subgéneros: la argumentación

${ }^{28}$ En buena parte de la exposición acerca de la argumentación jurídica desarrollada por los abogados, seguiremos a CALONJE, C., Técnicas de argumentación jurídica. 2a ed., Pamplona, Thomson Reuters, 2009. 
racional y la legal. La racional se refiere a la valoración de los hechos cometidos por el autor que originaron la controversia; y la legal se refiere a la interpretación del texto de la norma a la que hay que someter la resolución de la disputa, es decir, a la validez formal de su aplicación. La argumentación racional justifica la relatividad valorativa que envuelve el conflicto y su relación con el autor del mismo. La interpretación judicial justifica la aplicación formal de la ley ante el conflicto jurídico.

La fórmula básica utilizada desde la antigüedad por los abogados en el ejercicio de su profesión incluye: analizar, dictaminar, persuadir, justificar y convencer para influir en la decisión del juez. Convencer al cliente o al juez obliga al abogado a practicar el arte de la persuasión y ello, en detrimento de lo que la interpretación formal considera la verdadera demostración, la que conduce a la certeza de la ley. El objetivo del discurso del abogado defensor es tratar los sentimientos de la audiencia y conseguir que se le crea y se decida a su favor. En la mediación no existe esta persuasión, ya que el mediador no tiene ni que persuadir ni que convencer a ninguna de las partes de nada. El que quiere convencer tiene que pensar los conceptos destinados a demostrar lo que se propone y comunicar las razones para probarlo. La dificultad de la argumentación es de carácter intelectual porque consiste en usar el pensamiento para razonar. En la mediación no se atiende a las valoraciones sino que se deben de tratar las emociones (miedo, inseguridad, etc.) de las partes en conflicto.

El abogado debe saber en qué momento adecuado debe utilizar el discurso, el diálogo y el debate y con qué interlocutor (cliente, juez) debe utilizarlas. La acción comunicativa que el profesional del derecho vaya a utilizar en cada asunto dependerá del grado de defensibilidad que éste requiera, en función de si es un caso fácil, o un caso de duda seria o un caso de causa oscura u otros. Un conflicto no sólo implica un hecho con su correcta definición, su proceso, circunstancia o relación con otros hechos. Un conflicto implica, además y sobre todo, las diversas valoraciones que se dan acerca de ese hecho.

El mediador no puede aconsejar ni decidir cómo resolver el conflicto pero, por otro lado, debe velar para que el acuerdo al que lleguen las partes no sea contrario al ordenamiento jurídico. Y ello nos lleva a plantear varios interrogantes: ¿y si las partes están llegando a un acuerdo contrario a Derecho? ¿Y s i las partes están bloqueadas y no se les ocurren algunas soluciones factibles? El mediador, por su 
cumplimiento del deber de neutralidad e imparcial, ¿podrá orientarles o aconsejarles? Si en el ámbito jurídico podemos diferenciar entre las directrices de mandato (ordenan) y las permisivas (permiten), tendríamos que considerar que el mediador no se puede permitir dar órdenes ni mandatos. Como mucho, podrá apuntar algunas soluciones para que las partes puedan buscar la que consideren más apropiada para su caso y sus circunstancias. Con todo, el mediador debe ser cuidadoso para no vulnerar el deber de neutralidad.

Tal vez sea en la comunicación no verbal donde podamos encontrar más semejanzas entre el proceso judicial y la mediación. Tanto el abogado como el mediador deben cuidar su expresión gestual. En las acciones comunicativas se intercambian muchas cosas: expresiones faciales, una actitud, posturas corporales que transmiten un significado: tono de voz, movimientos, gestos. El lenguaje silencioso -por ejemplo, si el mediador dirige más su mirada a una de las partes en conflicto que a otra, si asienta con la cabeza cuando escucha su discurso, si en la exposición de alguna de las partes deja entrever una leve sonrisa, de forma que a la otra parte le pueda dar la impresión de que es irónica o de que no está creyendo lo que está exponiendo, etc. ${ }^{29}$.

\section{A MODO DE CONCLUSIÓN}

Frente a quienes conciben el ordenamiento jurídico como una forma de racionalidad práctica expresada a través de argumentaciones, se oponen las teorías que propugnan la posibilidad de aplicar modelos de racionalidad lógico-formal al Derecho. Estas tesis se apoyan en los aspectos técnicos del lenguaje jurídico, así como en la coherencia y sistematicidad de los ordenamientos jurídicos. Esta dimensión lógica de los sistemas normativos jurídicos permite proyectar para su conocimiento y elaboración determinadas aplicaciones informáticas. Hay un rico debate acerca de las posibilidades de aplicar el lenguaje jurídico y los procesos de argumentación jurídica a estructuras informáticas -como puedan ser la inteligencia

\footnotetext{
${ }^{29}$ El concepto de mediación que propone el Profesor F. Puy, incide precisamente en la aportación imprescindible del discurso verbal: "Una mediación es primero una acción física violenta dirigida a separar a dos personas trabadas en una pelea por algo que ambos piensan que es suyo, y por eso después un discurso verbal dulce que trata de persuadirles para que se reúnan en paz, recorriendo cada una la mitad de la distancia física y moral que las separa" (PUY, F., "La expresión "mediación jurídica': un análisis tópico, cit., p.30).
}

REVISTA DO DIREITO UNISC, SANTA CRUZ DO SUL No $37 \mid$ p. 179-206| JAN-JUN 2012 
artificial (IA) y los sistemas expertos jurídicos (SE)- en las que no hemos podido extendernos $^{30}$.

Las teorías de la argumentación jurídica pueden considerarse como una alternativa superadora tanto del planteamiento del determinismo formalista como del irracionalismo. La función crítica que le corresponde desempeñar a la Filosofía del Derecho puede desplegarse muy bien a través de las teorías de la argumentación jurídica que va a enfatizar la importancia de la razón práctica, además de subrayar que el Derecho ya no puede centrarse sólo en torno al papel protagonista de la norma, de manera que se acaba desplazando el interés de los juristas desde el elemento normativo hacia la decisión jurídica. Tópica, retórica y dialéctica se convierten en elementos imprescindibles en una filosofía jurídica que cada vez más, se une a la hermenéutica jurídica.

\section{REFERÊNCIAS}

ASíS ROIG, R. Sobre el razonamiento judicial, Madrid, McGrawHill, 1998.

El juez y la motivación en el Derecho. Madrid, Dykinson, 2005.

BELLOSO MARTÍN, N., "Revisitando la teoría de la argumentación: mediación jurídica versus proceso judicial”, en M. Otero Parga, (Coordinadora), en Tópica, Retórica y Dialéctica en la jurisprudencia, Ed. Universidad de Santiago de Compostela, Santiago, 2011.

- (Coordinadora), Estudios sobre mediación: La Ley de mediación familiar de Castilla y León, Consejería de Familia e Igualdad de Oportunidades de la Junta de Castilla y León, Valladolid, Indipress, 2006.

BERNAL PULIDO, C., "Los Derechos fundamentales y la teoría de los principios. ¿Es la teoría de los principios la base para una Teoría adecuada de los Derechos fundamentales de la Constitución española? En DOXA, nำ130, 2007

BUTTS GRIGGS, T., MUNDUATE, L., BARÓN, M. y MEDINA, F., "Intervenciones de mediación", en Gestión del conflicto, negociación y mediación, L. Munduate Jaca y F.J. Medina Díaz (Coordinadores), Madrid, Pirámide, 2006.

\footnotetext{
${ }^{30}$ PÉREZ LUÑO, A.E., Lecciones de Filosofía del Derecho,cit., p.114; en el ámbito español, sobre el tema, vid. los trabajos del profesor ámbito español, A.E. Pérez-Luño, pionero en el estudio de la informática aplicada al Derecho (Nuevas tecnologías, sociedad y derecho, Madrid, Fundesco, 1987; Manual de Informática y Derecho, Barcelona, Ariel, 1996; La tercera generación de derechos humanos, Madrid, Thomson-aranzadi, 2006);
}

REVISTA DO DIREITO UNISC, SANTA CRUZ DO SUL No $37 \mid$ p. 179-206| JAN-JUN 2012 
CALONJE, C., Técnicas de argumentación jurídica. $2^{2}$ ed., Pamplona, Thomson Reuters, 2009.

COMANDUCCI, P., AHUMADA, M…A., y GONZÁLEZ LAGIER, D., Positivismo jurídico y neconstitucionalismo. Madrid, Fundación Coloquio Jurídico Europeo.

DWORKIN, R., La justicia con toga. Trad. de M. Iglesias Vila e I. Ortiz de Urbina Gimeno. Madrid, Marcial Pons, 2007.

HART, H.L.A., "El nuevo desafío del positivismo jurídico", en Sistema, №36, trad. de F. Laporta, L. Hierro y J.R. del Páramo, 1990, pp.3-19. Este texto es el resultado de una conferencia impartida por Hart en la Universidad Autónoma de Madrid, el día 29 de octubre de 1979.

HERNÁNDEZ MARÍN, R., Las obligaciones básicas de los jueces. Madrid, Marcial Pons, 2005.

MORESO, J.J., "Alexy y la aritmética de la ponderación”, en M. Carbonell (Compil.), Argumentación jurídica. El juicio de ponderación. México, Porrúa, 2012.

PÉREZ LUÑO, Antonio Enrique. Lecciones de Filosofía del Derecho. Presupuestos para una Filosofía de la experiencia Jurídica. $2^{2}$ ed., Sevilla, Mergablum.

Wolters Kluwer, 2001.

El desbordamiento de las fuentes del Derecho. Madrid, La Ley-Grupo

PUY MUÑOZ, F., 'La expresión 'mediación jurídica': un análisis tópico, en Soleto Muñoz, H., y Otero Parga, M., (Coordinadoras), Mediación y solución de conflictos, Madrid, Tecnos, 2007.

. "La expresión 'argumentación jurídica' y sinónimas. Un análisis tópico", en La argumentación jurídica. Problemas de concepto, método y aplicación. Edición de F. Puy Muñoz y J. Guillén Portela, Universidad de Santiago de Compostela, 2004.

. F. y LÓPEZ MORENO, A., (Coordinadores). Manual de Filosofía del Derecho, Madrid, Colex, 2000.

RAMOS DUARTE, E.O., Neoconstitucionalismo e positivismo jurídico. As faces da teoria do Direito em tempos de interpretaçâo moral da Constituiçao, Sâo Paulo, Landy Editora, 2006.

Professor Convidado 